\title{
Prevalence of high blood pressure subtypes and its associations with BMI in Chinese children: a national cross-sectional survey
}

\author{
Yide Yang ${ }^{1}$, Bin Dong ${ }^{1,2}$, Shuo Wang ${ }^{1}$, Yanhui Dong ${ }^{1}$, Zhiyong Zou', Lianguo Fu ${ }^{3}$ and Jun Ma ${ }^{1 *}$
}

\begin{abstract}
Background: Data on prevalence and characteristics of different high blood pressure subtypes are lacking among Chinese children. Regarding the mechanistic differences between isolated systolic high blood pressure and isolated diastolic high blood pressure and their different impact on end organ diseases, it is necessary to examine the prevalence of different high blood pressure subtypes in Chinese children and explore their associations with adiposity.
\end{abstract}

Methods: Data were derived from the baseline data of a multi-centered cluster randomized controlled trial involving participants from China. High blood pressure was defined according to age-, gender- and height-specific 95th percentile developed by the National High Blood Pressure Education Program Working Group. Body mass index was used to classify underweight, normal weight, overweight and obesity.

Results: The prevalence of HBP was 10.2\% and $8.9 \%$ for boys and girls, respectively. Isolated systolic high blood pressure is the dominant high blood pressure subtype among Chinese boys aged 6-17 years and girls aged 1217 years, while isolated diastolic high blood pressure was the most common high blood pressure subtype in girls aged 6-11 years. In boys, the status of overweight doubled the risk of isolated systolic high blood pressure $(95 \% \mathrm{Cl}$, $1.73,2.31 ; P<0.001)$ compared with the normal weight group, and the risk for obese children was $4.32(95 \% \mathrm{Cl}, 3.81$, 4.90; $P<0.001)$. The corresponding odds ratios in girls were $2.04(95 \% \mathrm{Cl}, 1.68,2.48, P<0.001)$ for overweight, and 4.0 $(95 \% \mathrm{Cl}, 3.36,4.76, P<0.001)$ for obesity. Similar patterns were also observed in the association between combined systolic and diastolic high blood pressure and adiposity.

Conclusion: The distribution of high blood pressure subtypes in boys differed from those in girls, and boys with adiposity showed a higher risk of high blood pressure than their female counterpart. Difference in strength of association between isolated diastolic high blood pressure and isolated systolic high blood pressure with body mass index was also found. These results may aid current strategies for preventing and controlling pediatric hypertension.

Keywords: Blood pressure, Children, High blood pressure subtype, Obesity, Body mass index

\section{Background}

Elevated blood pressure (BP), especially high systolic blood pressure (SBP), is the leading cause of chronic disease worldwide. It is estimated that high SBP accounts for 10.4 million deaths and 208.1 million disabilityadjusted life-years [1,2]. Although current strategies of prevention, controlling and treatment focus on adults

\footnotetext{
* Correspondence: majunt@bjmu.edu.cn

${ }^{1}$ Institute of Child and Adolescent Health, School of Public Health, Peking University Health Science Center, 38 Xue Yuan Road, Haidian District, Beijing 100191, China

Full list of author information is available at the end of the article
}

$[3,4]$, pediatric high blood pressure (HBP), which could track into adulthood $[5,6]$ and result in a series of end-organ damages [7], has been an alarming public health problem in China [8].

Compared with diastolic blood pressure (DBP), high SBP had a more profound effect on myocardial infarction, angina and peripheral artery disease [9]. Mechanistically, it is reported that pediatric ISHBP represented an early stage of hypertension that might be modulated by the association between obesity and sympathetic nervous system hyperactivity, while no 
such phenomenon was found for IDHBP [10]. In adults, isolated hypertension(ISH) increases steadily with age, which is different from IDHBP [11]. However, it is unclear whether this age-related change in HBP exists in children as well.

To date, the prevalence of different HBP subtype is unknown in Chinese children. Although the close relationship between body mass index (BMI) and HBP has been well known [12], the associations between different HBP subtypes and BMI are rarely reported. In the present study, we investigated the gender and age disparity of HBP subtype among Chinese children based on a large national survey, and examined the strength of the association between BMI and HBP subtypes. Regarding the mechanistic differences between ISHBP and IDHBP, we hypothesized that the magnitude of association between ISHBP with BMI differs from that of IDHBP. These results have a potential to improve our understanding of pediatric HBP, and aid strategies for controlling and preventing HBP in children.

\section{Methods}

\section{Study design and participants}

Data were derived from the baseline data of a multicentered cluster randomized controlled trial involving Chinese children and adolescents from 7 provinces (Liaoning, Tianjin, Ningxia, Shanghai, Chongqing, Hunan and Guangdong) in September of 2013. The details of the recruitment process of participants were described in previous publication [13]. The study was approved by the Medical Ethical Committee of Peking University Health Science Center (IRB0000105213034). Written informed consent was obtained from all children and their parents. In total, 62,168 participants aged 6-17 years with complete data of body weight, height, and blood pressure were involved in the present study.

\section{Measurements and definitions}

All participants enrolled in the current study underwent physical examination to collect anthropometric data (weight and height) according to standard procedures by trained project members [14]. Weight was measured to the nearest $0.1 \mathrm{~kg}$ using a lever scale with the child wearing only underwear. Height was measured to the nearest $0.1 \mathrm{~cm}$ using a stadiometer according to a standardized protocol. BMI $\left(\mathrm{kg} / \mathrm{m}^{2}\right)$ was calculated as weight $(\mathrm{kg})$ divided by the height $(\mathrm{m})$ squared.

Participants were defined as underweight according to the Chinese national screening criteria for malnutrition of children aged 6-18 years [15]. According to the Chinese BMI percentile criteria for screening overweight and obesity of children aged 7-18 years, the participants with an age- and gender-specific BMI $\geq 95$ th percentile are defined as obese, while those with an age- and gender-specific BMI between 85th and 95th percentile are defined as overweight [16], and the BMI percentile criteria of overweight(between 85th and 95th percentile) and obesity $(\geq 95$ th percentile) for children younger than 7 years was defined according to a cut-offs criteria of a representative Chinese population [17]. After definition of underweight/overweight/obese (Additional file 1: Table S1 and Additional file 2: Table S2), other participants with an age- and gender-specific BMI less than the 85th percentiles are considered as normal-weight children.

$\mathrm{BP}$ was measured according to the recommendation of the National High Blood Pressure Education Program Working Group in Children and Adolescents [18] using standard clinical sphygmomanometer. BP measurements were taken $5 \mathrm{~min}$ after resting. If the measured difference was $>10 \mathrm{mmHg}$, measurement was repeated until the final two measures differed $\leq 10 \mathrm{mmHg}$, and the mean of the final two measures was used in analyses. Systolic BP was defined as the onset of "tapping" Korotkoff sound (K1), and diastolic BP was defined as the fifth Korotkoff sound (K5).

High BP is defined as SBP and/or DBP $\geq$ the age-, gender- and height-specific 95th percentile [18]. Isolated systolic high blood pressure (ISHBP) is defined as high SBP and normal DBP. Isolated diastolic high blood pressure (IDHBP) is defined as high DBP and normal SBP. A child who was both high in systolic and diastolic high blood pressure was identified as combined systolic and diastolic high blood pressure (SDHBP).

\section{Statistical analysis}

All data analyses were performed by SPSS for Windows (version 19.0, SPSS Inc., Chicago, IL, USA). Continuous variables were described as mean and standard deviation (s.d.) for, numerical data were described as rates. Chi square tests were used to compare the prevalence of HBP subtypes between boys and girls. Linear regression was used to analyze the associations between BMI and SBP/DBP, and $\beta$ with standard error (SE) were estimated. Logistic regression was used to analyze the associations between BMI categories and HBP or different HBP subtypes, and odds ratios (ORs) with 95\% CIs (confidence intervals) were also estimated.

\section{Results}

\section{Characteristic of the study population}

General characteristic of the population is presented in Table 1. A total of 62,168 children were involved in the present study, including 32,064 (51.6\%) boys and 30,104 (48.4\%) girls. As expected, boys had higher SBP and DBP than girls $(P<0.001)$. In terms of the distribution of HBP subtypes, boys had significantly higher prevalence of ISHBP than girls $(4.4 \%$ and $2.9 \%$ for boys and 
Table 1 Basic characteristics of 6-17 years old schoolchildren with different high blood pressure subtype

\begin{tabular}{|c|c|c|c|c|}
\hline \multirow[t]{2}{*}{ Variable } & \multirow{2}{*}{$\begin{array}{l}\text { Total } \\
\text { Mean(s.d.) }\end{array}$} & \multirow{2}{*}{$\begin{array}{l}\operatorname{Boys}(n=32,064) \\
\text { Mean(s.d.) }\end{array}$} & $\operatorname{Girls}(n=30,104)$ & \multirow[t]{2}{*}{ P } \\
\hline & & & Mean(s.d.) & \\
\hline$\overline{\text { Age }}$ & $10.8(3.3)$ & $10.7(3.3)$ & $10.9(3.3)$ & $<0.001$ \\
\hline $\mathrm{BMI}$ & $18.6(3.8)$ & $18.8(3.9)$ & $18.2(3.5)$ & $<0.001$ \\
\hline SBP & $104.3(12.2)$ & $105.7(12.5)$ & $102.8(11.6)$ & $<0.001$ \\
\hline DBP & $66.3(8.8)$ & $66.8(9.0)$ & $65.7(8.6)$ & $<0.001$ \\
\hline $\mathrm{HBP}$ & $5933(9.5 \%)$ & $3262(10.2 \%)$ & $2671(8.9 \%)$ & $<0.001$ \\
\hline Normal BP & $56,235(90.5 \%)$ & $28,802(89.8 \%)$ & $27,433(91.1 \%)$ & \\
\hline \multicolumn{5}{|l|}{ HBP subtype } \\
\hline ISHBPa & $2263(3.6 \%)$ & $1404(4.4 \%)$ & $859(2.9 \%)$ & \multirow[t]{3}{*}{$<0.001$} \\
\hline $\mathrm{IDHBP}$ & $1992(3.2 \%)$ & $1001(3.1 \%)$ & $991(3.3 \%)$ & \\
\hline SDHBP ${ }^{a}$ & $1678(2.7 \%)$ & $857(2.7 \%)$ & $821(2.7 \%)$ & \\
\hline \multicolumn{5}{|l|}{ nutritional status } \\
\hline Underweight $^{a}$ & $4456(7.2 \%)$ & $2528(7.9 \%)$ & $1928(6.4 \%)$ & \multirow[t]{4}{*}{$<0.001$} \\
\hline Normal weight ${ }^{a}$ & $43,121(69.4 \%)$ & $20,365(63.5 \%)$ & $22,756(75.6 \%)$ & \\
\hline Overweight $^{a}$ & $7888(12.7 \%)$ & $4823(15.0 \%)$ & $3065(10.2 \%)$ & \\
\hline Obesity $^{a}$ & $6703(10.8 \%)$ & $4348(13.6 \%)$ & $2355(7.8 \%)$ & \\
\hline
\end{tabular}

${ }^{a}$ values are numbers and proportions (\%). s.d. standard deviation, $B M I$ body mass index, SBP systolic blood pressure, DBP diastolic blood pressure, $H B P$ high blood pressure, $S D H B P$ combined systolic and diastolic high blood pressure, IDHBP isolated diastolic high blood pressure, ISHBP isolated systolic high blood pressure

girls, respectively) $(P<0.001)$. The prevalence of overweight and obesity were $15.0 \%$ and $13.6 \%$ in boys, and higher than those in girls $(P<0.001)$.

\section{Prevalence of HBP subtypes and the trend with age}

In total, $9.5 \%$ of the children had HBP, which were $10.2 \%$ and $8.9 \%$ for boys and girls, respectively (Table 1 ). In both sexes, there was an inverted U-shaped pattern in the prevalence of HBP, as well as different HBP subtypes, with age (Fig. 1, Additional file 3: Figure S1 and Additional file 4: Table S3). In general, HBP increased with age to the highest of $13.3 \%$ at 10 years old, then slowly decreased with age in boys. While in girls, HBP reached the peak prevalence $(15.9 \%)$ at 10 years old, then sharply decreased with age (Additional file 4: Table S3). Boys had higher prevalence of ISHBP than girls across age groups $(P<0.001$, Additional file 4 : Table S3). In boys, HBP and different HBP subtypes (ISHBP, IDHBP and SDHBP) reached the highest prevalence $(13.2 \%, 5.7 \%, 3.8 \%$ and $3.7 \%$ ) among 911 year age group. The same pattern was found in girls, with the highest prevalence of $14.3 \%, 3.8 \%, 5.6 \%$ and $4.8 \%$ for HBP, ISHBP, IDHBP and SDHBP observed in 9-11 year age group, respectively (Fig. 1 and Additional file 3: Figure S1). After adjusting for BMI and age, the trend in the prevalence of HBP and HBP subtypes over the age groups minimally changed in both sexes (Fig. 1 and Additional file 3: Figure S1).
Frequency distribution of HBP subtypes by age group The most common type of HBP subtype is ISHBP for boys in all age groups, ranging between $34.4 \%$ and $53.4 \%$ (Fig. 2). Nevertheless, IDHBP was the most common HBP subtype in girls 6 to 11 years old, while ISHBP was the primary HBP subtype in 12-17 years age group (Fig. 2).

\section{Association between adiposity and BP/HBP/HBP subtypes} When adjusted for age, SBP is significantly associated with BMI in boys and girls $(\beta=1.09$ and $1.01, P<0.001)$ and similar pattern was also observed in DBP $(\beta=0.60$ for boys and 0.57 for girls, $P<0.001$ ).

For boys, BMI was significantly associated with HBP $(\mathrm{OR}=1.15,95 \%$ CI: 1.14, 1.16; $P<0.001)$. Consistently, in girls BMI was significantly associated with HBP $(\mathrm{OR}=1.14,95 \% \mathrm{CI}: 1.13,1.15 ; P<0.001)$. Also, BMI was significantly associated with all HBP subtypes in boys and girls with age adjusted (all $P<0.001$, Table 2), especially for ISHBP and SDHBP. For boys, one-unit increment of BMI was associated with $18 \%$ higher risk of ISHBP and SDHBP (95\% CI: 1.16, 1.19; $P<0.001$ ). For boys, BMI was also significantly associated with HBP $(\mathrm{OR}=1.15,95 \% \mathrm{CI}: 1.14,1.16 ; P<0.001)$. In girls, oneunit increment of BMI was associated with $17 \%$ higher risk of ISHBP (95\% CI: 1.15, 1.19; $P<0.001$ ) and 15\% higher risk of SDHBP (95\% CI: 1.13, 1.18; $P<0.001$ ) (Table 3). For girls, BMI was significantly associated with HBP $(\mathrm{OR}=1.14,95 \% \mathrm{CI}: 1.13,1.15 ; P<0.001)$.

After adjustment for age, using the normal weight group as reference, underweight was a protective factor for the three HBP subtype in boys and girls (Table 3, all $P<0.05)$, while overweight and obesity are both risk factors for HBP and different HBP subtypes (all $P<0.05$ ). For the risk of HBP, overweight boys have an OR of 1.75 (95\% CI: $1.59,1.94 ; P<0.001$ ), compared with the reference group, and the risk increased to 3.31 (95\% CI: 3.03, 3.61; $P<0.001)$ for the obese boys. Meanwhile, overweight girls have an OR of 1.66 (95\% CI: 1.47, 1.87; $P<0.001$ ), and the risk increased to 2.84 (95\% CI: 2.54 , 3.18; $P<0.001$ ) for the obese girls.

In boys, overweight group has an OR of 2.00 (95\% CI: $1.73,2.31 ; P<0.001)$ for ISHBP, compared with the reference group, and the risk increased to 4.32 (95\% CI: $3.81,4.90 ; P<0.001)$ for the obese group. For IDHBP, overweight and obese group had ORs of 1.28 (95\% CI: $1.08,1.53 ; P=0.005)$ and 1.64 (95\% CI: 1.38, 1.94; $P<0.001)$ respectively, which were lower than those for ISHBP. For SDHBP, the corresponding values for overweight and obese group are 2.11 (95\% CI, 1.76, 2.54; $P<0.001)$ and 4.34 (95\% CI, 3.71, 5.09; $P<0.001)$ (Table 3). Similar pattern was also observed in girls, although the associations between HBP subtypes and BMI groups were of weaker amplitude compared with those in boys. 


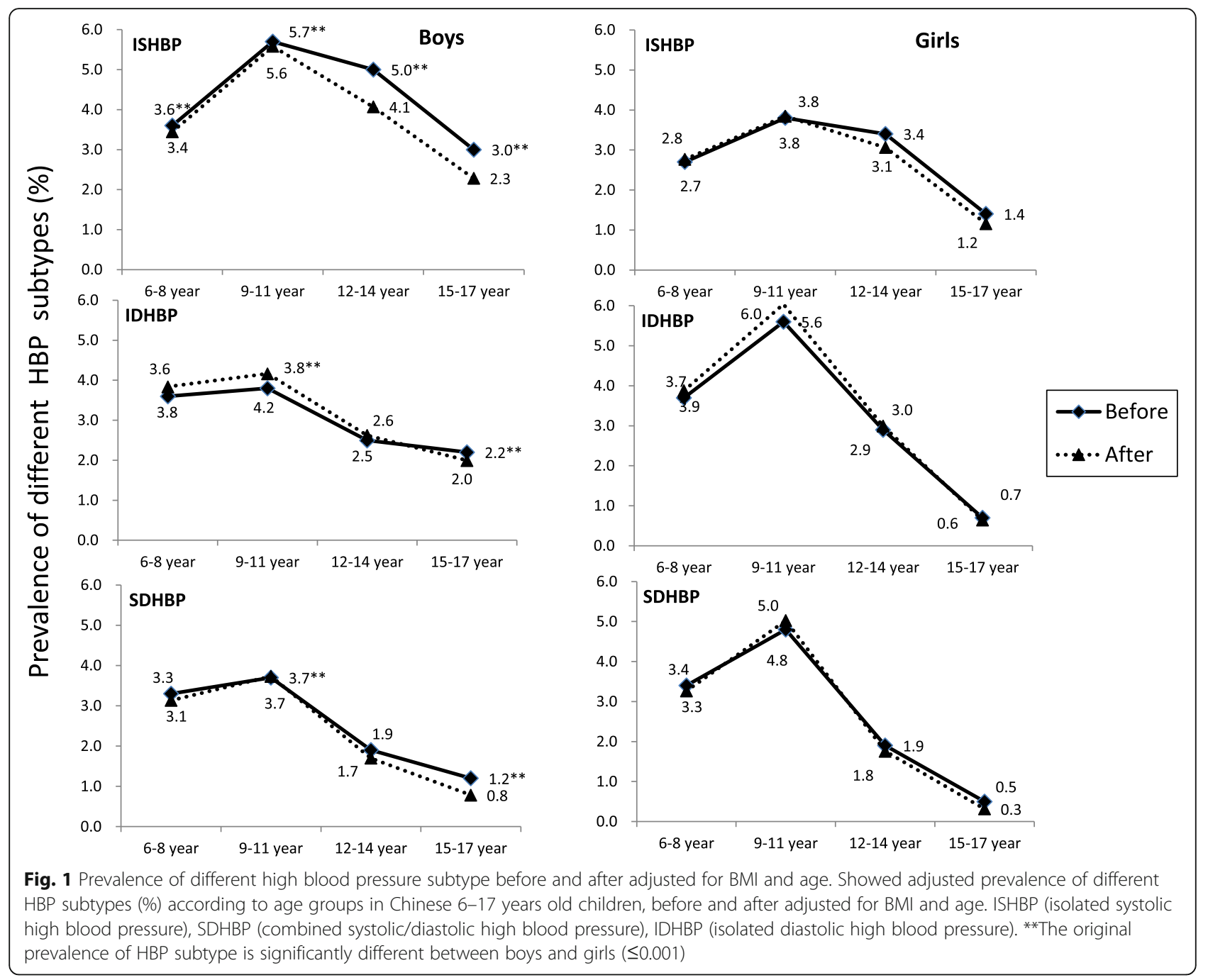

\section{Discussion}

The current study demonstrated that there is a gender difference of HBP subtypes distribution, and boys had a higher risk of ISHBP than girls. In boys aged 6 to 17 years old and girls aged 12 to 17 years old, ISHBP is the most common subtype of HBP in Chinese children. In girls aged 6 to 11 years old, IDHBP is the most frequent subtype. In addition, in both sexes, 9 to 11 years old were the age related to the highest prevalence of all types of HBP. These patterns were slightly changed when BMI was adjusted for. Furthermore, compared with IDHBP, a stronger association was observed between ISHBP and BMI.

To our knowledge, the present study is the first study concerning different HBP subtypes (ISHBP, IDHBP and SDHBP) prevalence and these subtypes' associations with BMI among Chinese young population. Our team previously reported the increasing trend in HBP from 2005 to 2010 using the Chinese National Surveys on
Students' Constitution and Health $(\mathrm{CNSSCH})$ [8]. That study showed that the prevalence of systolic and diastolic HBP in 2010 were $4.9 \%$ and $3.9 \%$ in boys and 3.5\% and $4.0 \%$ in girls, respectively. In the present study, the prevalence of SHBP and DHBP among 6- to 17-year-old children in 2013 is higher than those in 2010, with SHBP $7.05 \%$ and $5.58 \%$ for boys and girls respectively, and DHBP is $5.79 \%$ and $6.02 \%$ for boys and girls. Additionally, there is an inverted U-shaped pattern in the prevalence of HBP with age among various HBP subtypes and sex groups, with children aged 9-11 years old had the highest prevalence. These findings were lower than those observed in Swiss adolescents, who had the prevalence of HBP and ISHBP of $11.4 \%$ and $9.60 \%$, respectively [19]. Xu et al. used the same standard of HBP explored the prevalence of HBP by age and gender in Chinese children. In line with our results, boys had higher prevalence of HBP than girls, and HBP generally increased by age, but the trend with age were slightly 


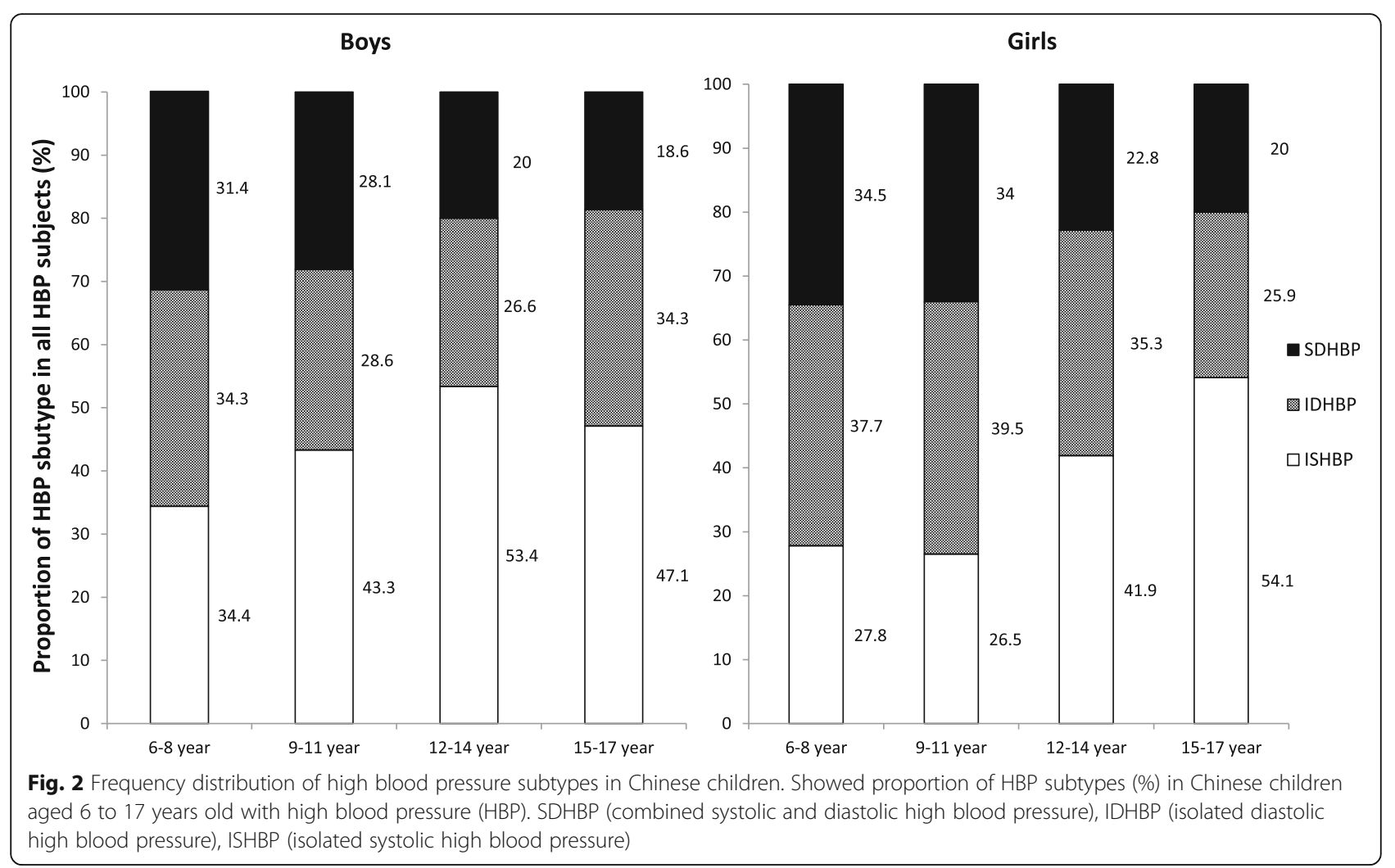

different. In Xu et al.'s study boys had a peak prevalence of HBP at age of 16 years, while girls had a peak prevalence of HBP at age of 10 years [20]. In our study, the prevalence of HBP is around 10 years old in both genders (Additional file 4: Table S3). The different age with

Table 2 Association between BMI and different BP traits

\begin{tabular}{lllll}
\hline Gender & BP traits & $\beta / O R$ & SE/95\% Cl & $P$ \\
\hline Boys & SBP & 1.09 & 0.02 & $<0.001$ \\
& DBP & 0.60 & 0.01 & $<0.001$ \\
& ISHBP & 1.18 & $(1.16,1.19)$ & $<0.001$ \\
& IDHBP & 1.07 & $(1.05,1.09)$ & $<0.001$ \\
& SDHBP & 1.18 & $(1.16,1.19)$ & $<0.001$ \\
& HBP & 1.15 & $(1.14,1.16)$ & $<0.001$ \\
Girls & SBP & 1.01 & 0.02 & $<0.001$ \\
& DBP & 0.57 & 0.02 & $<0.001$ \\
& ISHBP & 1.17 & $(1.15,1.19)$ & $<0.001$ \\
& IDHBP & 1.07 & $(1.05,1.09)$ & $<0.001$ \\
& SDHBP & 1.15 & $(1.13,1.18)$ & $<0.001$ \\
& HBP & 1.14 & $(1.13,1.15)$ & $<0.001$ \\
& OR & &
\end{tabular}

Adjusted for age. $O R$ odds ratio, $B M I$ body mass index, HBP high blood pressure, $S B P / D B P$ systolic/diastolic blood pressure, IDHBP isolated diastolic HBP, SDHBP combined systolic/diastolic HBP, IDHBP isolated diastolic HBP, ISHBP isolated systolic HBP. $\beta$ and SE standard error were obtained by linear regression analysis between $\mathrm{BMI}$ and SBP/DBP. OR and $95 \% \mathrm{Cl}$ were obtained by logistic regression analysis between BMI and HBP/HBP subtypes peak HBP prevalence may due to the different ethnicities. In addition, we also specified the ages with peak prevalence among each HBP subtypes, which were generally consistent with those of HBP.

In addition to previous studies that showed boys had significantly higher prevalence of HBP than girls $[8,21,22]$, our results presented boys related with an enhanced risk of ISHBP across age groups. Nevertheless, the situation of IDHBP was different, which revealed girls of 6 to 14 years old had a higher risk of IDHBP than their male counterparts.

Current study depicted the distribution of HBP subtype across age groups, which were different from those in adult population [23]. Increasing evidence has showed that the impact of ISHBP on the risk of cardiovascular diseases, including coronary heart disease, stroke, and related mortality and morbidity is stronger than IDHBP $[24,25]$. Moreover, high SBP could be tougher to control compared with high DBP [26]. Regarding the phenomenon that pediatric HBP could track into adulthood [5], the age and gender characteristics of prevalence of different HBP subtypes could be of vital importance when strategies for prevention and control HBP are developed in young population, which may further benefit their subsequent adulthood cardiovascular profile.

Additionally, the current study demonstrated the associations between different HBP/HBP subtypes and BMI. 
Table 3 Association between BMI categories and HBP or different HBP subtypes

\begin{tabular}{|c|c|c|c|c|c|}
\hline Gender & HBP subtypes & Nutritional status & OR & $95 \% \mathrm{Cl}$ & $P$ \\
\hline \multirow[t]{16}{*}{ Boys } & \multirow[t]{4}{*}{ ISHBP } & Normal weight & 1 (ref) & & \\
\hline & & Underweight & 0.38 & $(0.27,0.55)$ & $<0.001$ \\
\hline & & Overweight & 2.00 & $(1.73,2.31)$ & $<0.001$ \\
\hline & & Obese & 4.32 & $(3.81,4.90)$ & $<0.001$ \\
\hline & \multirow[t]{4}{*}{ IDHBP } & Normal weight & $1(\mathrm{ref})$ & & \\
\hline & & Underweight & 0.7 & $(0.52,0.93)$ & 0.013 \\
\hline & & Overweight & 1.28 & $(1.08,1.53)$ & 0.005 \\
\hline & & Obese & 1.64 & $(1.38,1.94)$ & $<0.001$ \\
\hline & \multirow[t]{4}{*}{ SDHBP } & Normal weight & 1 (ref) & & \\
\hline & & Underweight & 0.47 & $(0.30,0.73)$ & 0.001 \\
\hline & & Overweight & 2.11 & $(1.76,2.54)$ & $<0.001$ \\
\hline & & Obese & 4.34 & $(3.71,5.09)$ & $<0.001$ \\
\hline & \multirow[t]{4}{*}{$\mathrm{HBP}$} & Normal weight & 1 (ref) & & \\
\hline & & Underweight & 0.52 & $(0.43,0.64)$ & $<0.001$ \\
\hline & & Overweight & 1.75 & $(1.59,1.94)$ & $<0.001$ \\
\hline & & Obese & 3.31 & $(3.03,3.61)$ & $<0.001$ \\
\hline \multirow[t]{16}{*}{ Girls } & \multirow[t]{4}{*}{ ISHBP } & Normal weight & 1 (ref) & & \\
\hline & & Underweight & 0.52 & $(0.35,0.79)$ & 0.002 \\
\hline & & Overweight & 2.04 & $(1.68,2.48)$ & $<0.001$ \\
\hline & & Obese & 4.00 & $(3.36,4.76)$ & $<0.001$ \\
\hline & \multirow[t]{4}{*}{ IDHBP } & Normal weight & 1 (ref) & & \\
\hline & & Underweight & 0.62 & $(0.45,0.85)$ & 0.003 \\
\hline & & Overweight & 1.23 & $(1.01,1.51)$ & 0.038 \\
\hline & & Obese & 1.57 & $(1.28,1.93)$ & $<0.001$ \\
\hline & \multirow[t]{4}{*}{$\mathrm{SDHBP}$} & Normal weight & 1 (ref) & & \\
\hline & & Underweight & 0.46 & $(0.30,0.71)$ & $<0.001$ \\
\hline & & Overweight & 1.87 & $(1.53,2.29)$ & $<0.001$ \\
\hline & & Obese & 3.48 & $(2.90,4.16)$ & $<0.001$ \\
\hline & \multirow[t]{4}{*}{$\mathrm{HBP}$} & Normal weight & 1 (ref) & & \\
\hline & & Underweight & 0.55 & $(0.44,0.68)$ & $<0.001$ \\
\hline & & Overweight & 1.66 & $(1.47,1.87)$ & $<0.001$ \\
\hline & & Obese & 2.84 & $(2.54,3.18)$ & $<0.001$ \\
\hline
\end{tabular}

Adjusted for age. $O R$ odds ratio, $H B P$ high blood pressure, SDHBP combined systolic/diastolic high blood pressure, IDHBP isolated diastolic high blood pressure, ISHBP isolated systolic high blood pressure

Regarding the association between BMI and BP, similar results were found in other studies in Chinese children. Generally, children with overweight had a doubled higher risk of HBP, while quadrupled the risk was showed in children with obesity [27-31]. Though elevated $\mathrm{BMI}$ is associated with a significantly increased risk of ISHBP and SDHBP, the correlation between ISHBP and BMI is much stronger than that for IDHBP. These findings were consistent with a previous study conducted in a US population [32]. The possible mechanism for these differences in the magnitude of the association might be related with central pulsatile hemodynamics. Pierce et al. found that the adolescents with high BMI had increased left ventricular mass, high aortic wave amplitude, and systolic BP, but not diastolic BP, compared with their peers with normal weight [33]. Additionally, higher fat accumulation has been reported as an important independent predictor of aortic stiffness (aortic pulse-wave velocity), which is strongly associated with SBP [34]. Therefore, our finding suggested that intervention for reducing BMI may lead to a bigger benefit in controlling of ISHBP than IDHBP.

\section{Strengths and limitations}

The strengths of our study include that we used a relative large and representative sample. Additionally, our sample included participants with wide age range (from 6 to 17 years), which allowed us to explore the trend of pediatric HBP subtypes with age. However, there are also limitations. Firstly, the BP measurement was collected on one occasion, and the estimated prevalence of HBP may be overestimated. In the future study, BP measurements with multiple visits or using ambulatory blood pressure monitor would be better to identify HBP. Secondly, we did not collect the information about medication and salt consumption in this survey, which were warranted in our further study. Thirdly, this is a crosssectional study which is not able to provide causal inference for the association between BMI and BP.

\section{Conclusion}

Our study revealed that ISHBP is the predominant subtype of pediatric HBP among Chinese 6 to 17-year-old boys and 12- to 17-year-old girls, and IDHBP was the most common subtype of HBP in girls aged 6-11 years. An inverted U-shaped trend in prevalence of HBP subtypes across age was also observed. Regarding of the strength of association between ISHBP and BMI was stronger than those for IDHBP, children with ISHBP may obtain more benefices from obesity intervention. These findings may aid the strategies for preventing and controlling of hypertension in early life.

\section{Additional files}

Additional file 1: Table S1. Body Mass Index Reference Norm for Screening Overweight and Obesity Among Chinese children aged 7-18 years $\left(\mathrm{kg} / \mathrm{m}^{2}\right)$. (DOC $\left.69 \mathrm{~kb}\right)$

Additional file 2: Table S2. Body Mass Index Reference Norm for Screening underweight Among Chinese children aged 6-17 years (kg/m2). (DOC $87 \mathrm{~kb})$

Additional file 3: Figure S1. Showed the prevalence of HBP (\%) according to age groups in Chinese 6-17 years old children, before and after adjusted for BMI and age. HBP(high blood pressure). **The original 
prevalence of HBP subtype is significantly different between boys and girls $(\leq 0.001)$. ${ }^{*}$ The original prevalence of HBP subtype is significantly different between boys and girls ( $\leq 0.05)$. (PPT $187 \mathrm{~kb}$ )

Additional file 4: Table S3. The prevalence of HBP or different HBP subtypes among 6-17 years old Chinese schoolchildren. (DOC $47 \mathrm{~kb})$

\section{Abbreviations}

BMI: Body mass index; BP: Blood pressure; DBP: Diastolic blood pressure HBP: High blood pressure; IDH: Isolated diastolic hypertension; IDHBP: Isolated diastolic high blood pressure; ISH: Isolated systolic hypertension; ISHBP: Isolated systolic high blood pressure; SBP: Systolic blood pressure; SDH: Combined systolic and diastolic hypertension; SDHBP: Combined systolic and diastolic high blood pressure

\section{Acknowledgments}

We thank for all the supporting grants, namely, the Research Special Fund for Public Welfare Industry of Health (201202010) and the National Health and Medical Research Council of Australia (APP1042343). We thank all the children and parents for their participation in this study, also we want to thank for the head teachers of the schools for their help and cooperation in the research.

\section{Funding}

This study was supported by grants from the Research Special Fund for Public Welfare Industry of Health (201202010) and the National Health and Medical Research Council of Australia (APP1042343).

\section{Availability of data and materials}

The datasets analyzed in this study are available from the corresponding author (Jun Ma, majunt@bjmu.edu.cn) upon reasonable request.

\section{Authors' contributions}

$J M$ involved in the project administration, funding acquisition and supervision. ZZ, YY and LF carried out the study and collected the data. YY, $\mathrm{BD}, \mathrm{SW}$ and YD designed the study, analysed data and wrote the draft of the manuscript. All authors were involved in the writing and had read and approval of the final version of the paper.

\section{Ethics approval and consent to participate}

The study was approved by the Medical Ethical Committee of Peking University Health Science Center (IRB0000105213034). All participants and their parents signed informed consents voluntarily.

\section{Consent for publication}

Not applicable as no individual information is presented in the paper.

\section{Competing interests}

The authors declare that they have no competing interests.

\section{Publisher's Note}

Springer Nature remains neutral with regard to jurisdictional claims in published maps and institutional affiliations.

\section{Author details}

${ }^{1}$ Institute of Child and Adolescent Health, School of Public Health, Peking University Health Science Center, 38 Xue Yuan Road, Haidian District, Beijing 100191, China. ${ }^{2}$ Centre for Chronic Disease, School of Medicine, The University of Queensland, Brisbane, Australia. ${ }^{3}$ Department of Preventive Medicine, Bengbu Medical College, Bengbu, Anhui, China.

Received: 25 November 2016 Accepted: 20 June 2017

\section{Published online: 26 June 2017}

\section{References}

1. Lawes CM, Vander HS, Law MR, Elliott P, MacMahon S, Rodgers A. Blood pressure and the global burden of disease 2000. Part 1: estimates of blood pressure levels. J Hypertens. 2006;24(3):413-22.

2. Forouzanfar $M H$, Alexander $L$, Anderson HR, Bachman VF, Biryukov $S$, Brauer $\mathrm{M}$, et al. Global, regional, and national comparative risk assessment of 79 behavioural, environmental and occupational, and metabolic risks or clusters of risks in 188 countries, 1990-2013: a systematic analysis for the global burden of disease study 2013. Lancet. 2015:386(10010):2287-323.

3. James PA, Oparil S, Carter BL, Cushman WC, Dennison-Himmelfarb C, Handler J, et al. 2014 evidence-based guideline for the management of high blood pressure in adults: report from the panel members appointed to the eighth joint National Committee (JNC 8). JAMA. 2014;311(5):507-20.

4. Chobanian AV, Bakris GL, Black HR, Cushman WC, Green LA, Izzo JJ, et al. The seventh report of the joint National Committee on prevention, detection, evaluation, and treatment of high blood pressure: the JNC 7 report. JAMA. 2003;289(19):2560-72.

5. Chen $X$, Wang $Y$. Tracking of blood pressure from childhood to adulthood: a systematic review and meta-regression analysis. Circulation. 2008:117(25):3171-80

6. Howe LD, Chaturvedi N, Lawlor DA, Ferreira DL, Fraser A, Davey SG, et al. Rapid increases in infant adiposity and overweight/obesity in childhood are associated with higher central and brachial blood pressure in early adulthood. J Hypertens. 2014;32(9):1789-96.

7. Daniels SR, Pratt CA, Hayman LL. Reduction of risk for cardiovascular disease in children and adolescents. Circulation. 2011:124(15):1673-86.

8. Dong B, Wang Z, Song Y, Wang HJ, Ma J. Understanding trends in blood pressure and their associations with body mass index in Chinese children, from 1985 to 2010: a cross-sectional observational study. BMJ Open. 2015;5(9):e9050.

9. Rapsomaniki E, Timmis A, George J, Pujades-Rodriguez M, Shah AD, Denaxas $\mathrm{S}$, et al. Blood pressure and incidence of twelve cardiovascular diseases: lifetime risks, healthy life-years lost, and age-specific associations in 1.25 million people. Lancet. 2014;383(9932):1899-911.

10. Sorof JM, Poffenbarger T, Franco K, Bernard L, Portman RJ. Isolated systolic hypertension, obesity, and hyperkinetic hemodynamic states in children. J Pediatr. 2002;140(6):660-6.

11. Izzo JJ, Levy D, Black HR. Clinical advisory statement. Importance of systolic blood pressure in older Americans. Hypertension. 2000;35(5):1021-4.

12. Ma J, Wang Z, Dong B, Song Y, Hu P, Zhang B. Body fat and blood pressure: comparison of blood pressure measurements in Chinese children with different body fat levels. Br J Nutr. 2012;108(9):1672-7.

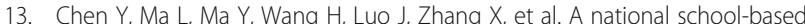
health lifestyles interventions among Chinese children and adolescents against obesity: rationale, design and methodology of a randomized controlled trial in China. BMC Public Health. 2015;15:210.

14. Li XH, Lin S, Guo $H$, Huang $Y$, Wu L, Zhang $Z$, et al. Effectiveness of a school-based physical activity intervention on obesity in school children: a nonrandomized controlled trial. BMC Public Health 2014;14:1282.

15. Institute of Child and Adolescent Health of Peking University. Screening standard for malnutrition of school-age children and adolescents. China Standards Press (Standard NO:WS/T 456-2014); 2014. [in Chinese].

16. Ji CY. Report on childhood obesity in China (1)-body mass index reference for screening overweight and obesity in Chinese school-age children. Biomed Environ Sci. 2005:18(6):390-400.

17. Li H, Zong XN, Ji CY, Mi J. [Body mass index cut-offs for overweight and obesity in Chinese children and adolescents aged 2-18 years]. Zhonghua Liu Xing Bing Xue Za Zhi. 2010;31(6):616-620.

18. The fourth report on the diagnosis, evaluation, and treatment of high blood pressure in children and adolescents. Pediatrics. 2004;114(2 Suppl 4th Report): 555-576.

19. Chiolero A, Cachat F, Burnier M, Paccaud F, Bovet P. Prevalence of hypertension in schoolchildren based on repeated measurements and association with overweight. J Hypertens. 2007;25(11):2209-17.

20. Xu T, Zhu G, Liu J, Han S. Gender-specific prevalence and associated risk factors of high normal blood pressure and hypertension among multi-ethnic Chinese adolescents aged 8-18 years old. Blood Press. 2015;24(3):189-95.

21. Rosner B, Cook NR, Daniels S, Falkner B. Childhood blood pressure trends and risk factors for high blood pressure: the NHANES experience 1988-2008. Hypertension. 2013;62(2):247-54.

22. Zhang YX, Zhou JY, Zhao JS, Chu ZH. Urban-rural and regional disparities in the prevalence of elevated blood pressure among children and adolescents in Shandong. China Int J Cardiol. 2014;176(3):1053-5.

23. Franklin SS, Jacobs MJ, Wong ND, L'Italien GJ, Lapuerta P. Predominance of isolated systolic hypertension among middle-aged and elderly US 
hypertensives: analysis based on National Health and nutrition examination survey (NHANES) III. Hypertension. 2001;37(3):869-74.

24. He J, Whelton PK. Elevated systolic blood pressure as a risk factor for cardiovascular and renal disease. J Hypertens Suppl. 1999;17(2):S7-S13.

25. Hozawa A, Ohkubo T, Nagai K, Kikuya M, Matsubara M, Tsuji I, et al. Prognosis of isolated systolic and isolated diastolic hypertension as assessed by self-measurement of blood pressure at home: the Ohasama study. Arch Intern Med. 2000;160(21):3301-6.

26. Black HR. The paradigm has shifted, to systolic blood pressure. Hypertension. 1999;34(3):386-7.

27. Liang JJ, Chen YJ, Jin Y, Yang WH, Mai JC, Ma J, et al. Comparison of adiposity measures in the identification of children with elevated blood pressure in Guangzhou. China J Hum Hypertens. 2015;29(12):732-6.

28. Dong B, Wang Z, Wang HJ, Ma J. Associations between adiposity indicators and elevated blood pressure among Chinese children and adolescents. J Hum Hypertens. 2015;29(4):236-40.

29. Dong J, Guo XL, Lu ZL, Cai XN, Wang HC, Zhang JY, et al. Prevalence of overweight and obesity and their associations with blood pressure among children and adolescents in Shandong. China Bmc Public Health. 2014;14:1080.

30. Zhang YX, Zhao JS, Chu ZH, Zhou JY. Prevalence of elevated blood pressure is associated with the increasing prevalence of obesity among children and adolescents in Shandong, China. Int J Cardiol. 2015;201:150-1.

31. Meng L, Liang Y, Liu J, Hu Y, Yan Y, Mi J. Prevalence and risk factors of hypertension based on repeated measurements in Chinese children and adolescents. Blood Press. 2013;22(1):59-64

32. Grebla RC, Rodriguez CJ, Borrell LN, Pickering TG. Prevalence and determinants of isolated systolic hypertension among young adults: the 1999-2004 US National Health and Nutrition Examination Survey. J Hypertens. 2010;28(1):15-23.

33. Pierce GL, Pajaniappan M, DiPietro A, Darracott-Woei-A-Sack K, Kapuku GK. Abnormal central pulsatile hemodynamics in adolescents with obesity: higher aortic forward pressure wave amplitude is independently associated with greater left ventricular mass. Hypertension. 2016;68(5):1200-7.

34. Wildman RP, Mackey RH, Bostom A, Thompson T, Sutton-Tyrrell K. Measures of obesity are associated with vascular stiffness in young and older adults. Hypertension. 2003;42(4):468-73.

\section{Submit your next manuscript to BioMed Central and we will help you at every step:}

- We accept pre-submission inquiries

- Our selector tool helps you to find the most relevant journal

- We provide round the clock customer support

- Convenient online submission

- Thorough peer review

- Inclusion in PubMed and all major indexing services

- Maximum visibility for your research

Submit your manuscript at www.biomedcentral.com/submit

) Biomed Central 